\title{
Del absurdo y el Eros: Albert Camus.
}

\section{Of the absurd and the Eros: Albert Camus.}

DOI: $10.32870 /$ sincronia.axxv.n80.6b21

\author{
Mauricio Simón Rumualdo Ávila \\ Escuela Nacional de Antropología e Historia (MÉXICO) \\ CE: mauricio.rumualdoav@gmail.com / ID ORCID: 0000-0003-3452-2467
}

Esta obra está bajo una Licencia Creative Commons Atribución-NoComercial 4.0 Internacional

Recibido: $31 / 03 / 2021$

Revisado: 30/04/2021

Aprobado: 16/06/2021

\section{RESUMEN}

Este artículo se trata de un estudio sobre la relación entre la filosofía del absurdo y el Eros en la obra literaria del escritor francés Albert Camus, con la finalidad de demostrar que ambas concepciones resultan incompatibles. Para ello, los distintos escenarios del absurdo que se presentan en las obras de Camus y sus implicaciones en el Eros fueron analizados. Esta relación fue abordada a partir de las visiones de los personajes que actúan con presencia o ausencia de Eros

Palabras clave: Absurdo, Eros, Camus, Thanatos.

\section{ABSTRACT}

This articule is a study about the relation between the philosophy of the absurd and the Eros in the literary work of the french writer Albert Camus, with the aim to show how these two conceptions are incompatible. To do this, the different settings of the absurd that are present in the books of Camus and their implications with the Eros were analyzed. This relation was approached with the visions of the characters that act with the presence or ausence of Eros

Keywords: Absurd, Eros, Camus, Thanatos. 
El extranjero (1942), la primera novela de Albert Camus, se ha estudiado desde perspectivas como el existencialismo, la filosofía del absurdo o la crítica hacia la inhumanidad de la sociedad moderna capitalista, pero también puede abordarse desde su ausencia de Eros. En el libro, Meursault es un hombre que se muestra indiferente ante todo y que aparenta insensibilidad hacia sus conocidos más íntimos, porque es consciente de que "todo el mundo sabe que la vida no vale la pena de ser vivida" (Camus, 2016, p. 111). Repudiado por su sociedad, Meursault es un extranjero que no cumple con ninguna regla moral y que se presenta inhumano, como lo demuestra el hecho de no haber llorado la muerte de su madre y de haber cometido un homicidio tan solo porque había hecho mucho calor el día en que se paseaba por la playa con un revólver en sus manos. Aún más, para mayor rechazo de sus contemporáneos, Meursault fue más odiado por no mostrar ningún gesto humano al declararse culpable en su juicio, porque él se mostraba como un hombre incapaz de sentir arrepentimiento o miedo, uno que vive por vivir, que no cree en Dios y que solamente vive para esperar la muerte: Meursault es un hombre sin Eros.

Paradójicamente, el estilo de vida indiferente de Meursault tampoco puede entenderse como una negación existencialista de la vida, sino más bien un vivir en lo absurdo, que surge entre el individuo y el mundo: "Lo absurdo nace de esta confrontación entre el llamamiento humano y el silencio irrazonable del mundo" (Camus, 2016, p. 313). En este sentido, Meursault es un ser pasivo que se muestra indiferente, porque la vida no vale la pena de ser vivida, pero no porque la niegue, sino porque es consciente de lo absurdo que es vivirla: "Desde el momento en que se le reconoce, el absurdo se convierte en una pasión, en la más desgarradora de todas" (Camus, 2016, p. 309). Por todo esto, el papel de Meursault en el mundo es el de un hombre que acaso viva bajo la "pasión" de lo absurdo de la vida y del mundo, pero que se muestra como un extranjero con su sociedad, porque ese "no valer la pena" se convierte en una ausencia del Eros.

El erotismo, comúnmente relacionado con el enamoramiento y el deseo sexual, también involucra un carácter de vitalidad y de empatía, que son permitidos a partir de la otredad. Para que exista Eros, en cualquiera de sus acepciones, es necesaria la existencia del otro, ese otro que 
arrebata, motiva e inspira: "El Eros arranca al sujeto de sí mismo y lo conduce fuera, hacia el otro" (Han, 2018, p. 10). Por tanto, Meursault es un hombre que no tiene pulsión de vida, que no se place de la vitalidad de vivir con Eros. Tampoco es un hombre con pulsión de muerte, porque no se place en la destrucción, sino que se place en la indiferencia por el absurdo. De esta manera, sin importarle la vida y la muerte, Meursault es un punto medio al que, si le da igual vivir, también la da igual la vida de los otros.

Las relaciones afectivas de Meursault, más allá del rechazo social provocado por su crimen, exhiben su falta de empatía y deseo hacia los otros que lo rodean. María Cardona, la mujer que se enamora de él, se ve obligada a aceptar todas las indiferencias de Meursault como pareja, porque lo ama. En cambio, Meursault, aunque la corresponde y complace sexualmente, no la ama. Para Meursault, estar acompañado de María significaba cumplir con las costumbres afectivas de la vida absurda. Así, el posible Eros que Meursault podría sentir hacia María nunca va más allá del mero deseo sexual, porque ella nunca le importa ni le interesa como otredad, sino como cuerpo que puede satisfacer sus necesidades fisiológicas.

A pesar de su indiferencia, de ser un total extranjero del que nada se puede esperar, Meursault es un hombre pasivo que, en su no importarle nada, lo acepta todo. Cuando su vecino Raimundo Sintés le pide escribir una carta para su ex pareja y testificar en su contra, Meursault no ve ningún problema en corresponderle. Tampoco le costó nada decirle a María que se casaría con ella cuando hablaron del tema, porque el hecho de formar una familia le parecía una más de las condiciones acostumbradas de la vida absurda. Ni siquiera pudo negarse cuando su jefe de la oficina le pidió que se mudara a París para laborar en uno de sus nuevos proyectos, porque le daba igual hacer su vida donde fuera y con las condiciones que fueran. Refugiado en su pasividad de aceptarlo todo porque nada vale la pena, Meursault es un hombre que vive y se relaciona sin Eros, porque los otros no existen, porque la negación tampoco vale la pena en un mundo donde un individuo vive solamente porque tiene que hacerlo.

En cambio, el protagonista de Calígula actúa de una manera tan opuesta a Meursault que, no obstante, termina por ser también un hombre sin Eros. Escrita por Camus años antes de su estreno 
en 1945, Calígula es una obra de teatro acerca del emperador romano y sus actos de locura, que lograron desatar la rebelión de sus patricios. Al contrario de Meursault, Calígula es un hombre con deseos propios que, en su actuar excéntrico, también vive del absurdo. Así opina de él uno de sus consejeros: "Cayo es un idealista, todo el mundo lo sabe. Sigue su idea, eso es todo. Y nadie puede prever a dónde lo llevará" (Camus, 2016, p. 16). Hombre de poder, Calígula se convierte en un tirano al perder a su hermana Drusila, con la que mantenía relaciones incestuosas. Perdido el amor, ese Eros de desvivirse por su hermana, Calígula pasó a gobernar con crueldad, ya que en tres años ordenó la ejecución del padre del poeta Escipión y del hijo de Lépido, la prostitución de la mujer de Octavio y la confiscación de los bienes de los patricios. Sin respetar la posición social de sus allegados en el Imperio, Calígula terminó por convertirse en un extranjero al que se le califica de loco por actuar en contra de los privilegios de los privilegiados. Pero este actuar en contra de los patricios no fue en beneficio del pueblo romano, que sufría peores violaciones, sino del propio Calígula.

Mientras que Meursault fue un hombre que vivió recluido en su indiferencia sin pretender hacer daño a su sociedad (salvo el homicidio cometido en una circunstancia desafortunada), Calígula, al ser el emperador, se dedicó a afectar al Imperio para poder complacer su visión individualista del mundo. Empero, Calígula, como Meursault, sí era consciente de que la vida no vale la pena de ser vivida, sólo que Calígula sí actuó en afectación de los otros, a los que quiso obligar a pensar como él a través del miedo, para que fueran conscientes de que la vida es absurda. Por esto último, Calígula es un hombre sin Eros porque se aprovecha de su situación en el poder para cumplir sus propios caprichos del absurdo a costa de los otros, que no tienen participación alguna en su visión individualista del mundo, en el que la negación no tiene cabida.

Al descubrir el plan que Quereas había elaborado para asesinarlo, Calígula le pide una explicación a su consejero, el cual le confiesa: "tengo ganas de vivir y de ser feliz. Creo que no es posible ni lo uno ni lo otro llevando lo absurdo hasta sus últimas consecuencias. Soy como todo el mundo" (Camus, 2016, p. 42). Pero Calígula no era como todo el mundo, sino un extranjero narcisista que llevaba al extremo sus ideas del absurdo. Es por esto que los patricios, al verse 
afectados, deciden traicionar al emperador y asesinarlo. Sin embargo, esta traición fue provocada por el mismo Calígula que, bajo una pulsión por la muerte, quiere dejar de vivir y permite que sus allegados puedan vengarse. De esta manera, Calígula apuesta por el Thanatos, que es lo contrario al Eros, porque él sabe que "los hombres mueren y no son felices" (Camus, 2016, p. 15) y que "los hombres lloran porque las cosas no son lo que deberían ser" (Camus, 2016, p. 19).

Por todo esto, para Calígula era preferible la muerte, porque sólo con ella podía ser verdaderamente libre de una vida en la que nada importaba, ni siquiera el amor, porque la muerte de su hermana Drusila le había mostrado que el amor no bastaba para escapar del absurdo, porque el amor y la pena no son nada cuando la vida es irracional. Así se lo confiesa a Cesonia, su amante, mientras la estrangula en la última escena de la obra:

Eso es ser feliz, esa es la felicidad: esta insoportable liberación, este universal desprecio, la sangre, el odio a mi alrededor, este aislamiento sin igual del hombre que tiene toda su vida bajo la mirada, la alegría desmedida del asesino impune, esta lógica implacable que tritura vidas humanas (Ríe), que tritura, Cesonia, para lograr por fin la soledad eterna que deseo (Camus, 2016, p. 54).

Esta felicidad de la que habla Calígula es también la felicidad de Meursault al saber que será ejecutado frente a su sociedad y la felicidad de Sísifo cuando baja para recoger la roca que ha caído de la cima: "Toda la alegría silenciosa de Sísifo consiste en eso. Su destino le pertenece. Su roca es su cosa. Del mismo modo, el hombre absurdo, cuando contempla su tormento, hace callar a todos los ídolos" (Camus, 2016, p. 361). Para Camus, la felicidad es inseparable del absurdo, porque la felicidad es tomar consciencia del absurdo, es encarar la confrontación entre individuo e irracionalidad del mundo. Por eso, con la muerte, Meursault y Calígula se liberan de la negación del absurdo de sus sociedades. En soledad, estos extranjeros del mundo, que han decidido despojarse del Eros, se entregan a la pasión del absurdo del cual logran liberarse con la muerte.

En cambio, ninguno de este tipo de personajes puede mostrarse en La peste (1947). A diferencia de El extranjero y Calígula, La peste es una novela con diversos personajes que hacen 
frente a un encierro obligado, confinamiento que se convierte en un exilio invertido en el cual la población de Oran se separa del resto del mundo. De esta manera, los sujetos que cohabitaban en la ciudad tuvieron que confrontar la epidemia con una organización y lucha comunitaria, es decir, que se vieron forzados a colaborar unidos para luchar por el impulso de vida: "Ya no había destinos individuales, sino una historia colectiva que era la peste y sentimientos compartidos por todo el mundo" (Camus, 2016, p. 220). Pero esta lucha no estuvo exenta del dolor, el miedo y el egoísmo. El confinamiento, a la vez que provocó la unión de los habitantes de Oran, también logró transformarlos.

El protagonista principal de La peste es el doctor Bernard Rieux, dirigente de la comisión sanitaria que se hace cargo de sobrellevar la epidemia. En él, podemos observar el cambio más radical entre los personajes. Mientras que en un inicio se preocupa por sus allegados y se involucra en solicitar el cierre de la ciudad para la seguridad del mundo, su sentido de empatía hacia los otros se va perdiendo conforme transcurre el tiempo. Naturalmente, su función como doctor lo hace convivir diariamente con pacientes que terminan muriendo. Testigo del dolor ajeno, la muerte termina por convertirse en una costumbre para el doctor que, incapaz de salvar a la gente frente a un virus incurable, sólo puede preparar a sus pacientes para la muerte:

Uno se cansa de la piedad cuando la piedad es inútil. Y en este ver cómo su corazón se cerraba sobre sí mismo, el doctor encontraba el único alivio de aquellos días abrumadores. Sabía que así su misión sería más fácil, por esto se alegraba. (Camus, 2016, p. 177).

El punto máximo de la "indiferencia" del doctor se da al final de la novela, cuando se entera de la muerte de su esposa, a la que es incapaz de llorar: “...en su sufrimiento no había sorpresa. Desde hacía meses y desde hacía dos días era el mismo dolor el que continuaba" (Camus, 2016, p. 287).

No obstante, la transformación del doctor Rieux es distinta a la de Meursault, porque su indiferencia o, mejor dicho, su "inmunidad" hacia la muerte de los otros surgió como resultado de su costumbre, de una vida pandémica que detuvo el tiempo por un año en la ciudad de Oran para convertirlo todo en desolación, miedo y dolor. En este sentido, la muerte de su esposa, a la que dejó 
de ver desde antes de que iniciara la epidemia, es una muerte más, a las miles de pérdidas que el doctor Rieux despidió en un año completo de convivencia con la muerte. Pero su falta de expresión de tristeza no significaba que el doctor Rieux se hubiese convertido en un hombre inhumano, porque amaba a su madre y había sufrido la pérdida de los niños que habían muerto por la peste, sino que simplemente había perdido la capacidad de llorar y de dolerse, porque este último sentimiento se había convertido en el estado natural de su vida cotidiana.

Por lo tanto, el levantamiento de la pandemia y la reapertura de Oran provocó que la población, entre el pesimismo y la esperanza, buscara la felicidad al volver hacia el mundo antes conocido. Sobrevivientes que compartieron un año de lucha contra la muerte, los personajes de La peste terminan por demostrarnos que "hay en los hombres más cosas dignas de admiración que de desprecio" (Camus, 2016, p. 296). Para estos sobrevivientes, la reapertura significaba la oportunidad de "recomenzar", de terminar con el estado del absurdo en que se habían visto inmersos dentro de la peste para reencontrarse con el mundo ordinario que estaba moderado por Dios y los valores sociales. Obstinados en vivir, los personajes de La peste se inclinan por la vida "feliz" por la que abogaba Quereas, esa felicidad ilusoria que se opone a todo ser consciente del absurdo, como son Muersault y Calígula. En lugar de la soledad y la indiferencia por el Eros, los sobrevivientes de Oran aprendieron a defender su vida, a actuar con empatía y a buscar la ternura humana.

Este ejercicio invertido del Eros también puede observarse en Los justos (1949), la última obra de teatro de Camus, en el cual un grupo de terroristas llevan a cabo un atentado contra el duque Sergio para provocar la rebelión del pueblo ruso. Paradójicamente, este grupo de revolucionarios necesita de la muerte de las personas en el poder para poder permitir la vida entre los oprimidos. Hermanados por su asociación al partido comunista, estos camaradas luchan de manera compartida para terminar con el despotismo del Imperio ruso. Bajo una pulsión de vida que permita la liberación del pueblo ruso, estos terroristas optan por sacrificarse para permitir la salvación de los otros. De esta manera, su sacrificio está orientado hacia la posibilidad de vida del resto de los hombres y mujeres reprimidos por las injusticias del Imperio. Así, el amor que siente 
Yanek Kaliayev, el responsable de tirar la bomba al carruaje del duque, se refiere a uno colectivo: "Pero eso es el amor; darlo todo, sacrificarlo todo sin esperanza de reciprocidad" (Camus, 2016, p. 392).

En cuanto que el acto principal recae en sus manos, Kaliayev es el personaje más importante de la obra, porque se trata de un hombre que sacrifica su amor personal por Dora, su compañera del atentado, y su propia vida. Una vez cometido el asesinato, para Kaliayev no hay más destino que la condena de muerte, sentencia necesaria para probarse a él mismo que no ha matado para terminar con la vida de otro hombre, sino para acabar con el despotismo. Se trata de un acto de "justicia" que lo ha preparado para morir feliz, consciente de que ha sacrificado su vida para un bien mayor para su sociedad. Así, a partir del seguimiento de una ideología, Kaliayev y el resto de los integrantes de su grupo buscan sacrificarse para cambiar las condiciones de vida que su sociedad ha sufrido con el Imperio: es ese impulso de vida por la liberación que llevó a los patricios a matar a Calígula y a los habitantes de Oran para combatir la epidemia.

La obra de Camus, tan corta y compleja, contiene una gran cantidad de significados distintos que giran en torno al absurdo, esa consciencia de la vida inútil que también puede encontrarse en la carcajada de El lobo estepario de Hermann Hesse o en el desarrollo burocrático de El proceso de Kafka. De diferente planteamiento, todas las novelas y obras dramáticas de Camus, que ubican a sus personajes en una situación del absurdo, nos han permitido observar los distintos niveles del Eros y su ausencia. Por un lado, se encuentran los extranjeros solitarios, seres como Meursault, Calígula y Jean Baptiste Clamence, ese protagonista hostigador, simpático y narcisista de La caída (1956) que ha hecho de su vida un absurdo en el que ha enloquecido. A su vez, estos personajes, que son conscientes del absurdo, manifiestan diferencias en su manera de vivirlo, para finalmente terminar muriendo. De manera contraria, están los personajes que, comúnmente mostrados dentro de una colectividad, combaten el estado del absurdo para restituir la vida común. A esta clase pertenecen los asesinos de Calígula, los habitantes de Oran y los comunistas rusos. Como hemos visto, de estos conjuntos destacan Quereas, el doctor Rieux y Kaliayev, que también cuentan con situaciones particulares que los ha hecho convivir con el absurdo. 
En conclusión, el manejo del absurdo y sus manifestaciones en la obra de Camus también puede abordarse como un manejo del Eros. Sin embargo, ambas concepciones no son opuestas, aunque sí incompatibles. La indiferencia hacia la vida ciertamente no puede corresponder con el Eros, sino con su ausencia, pero tampoco se trata de una caída en el Thanatos. Surgido de la contradicción entre la situación del individuo frente al mundo irracional, el absurdo es una concepción en la que no basta ni el Eros ni el Thanatos. La muerte, a la que terminan por entregarse muchos de los personajes de Camus, es antes una liberación del absurdo que una pulsión de muerte, porque con ella se puede superar la inutilidad de la vida humana: "Sí, el hombre es su propio fin. Y es su único fin. Si quiere ser algo, tiene que serlo en esta vida. Ahora lo sé de sobra" (Camus, 2016, p. 343).

\section{Referencias}

Camus, A. (2016). Albert Camus Obras maestras. México: EMU.

Han, B. (2018). La agonía del Eros [Versión electrónica]. España: Herder. 